University of Nebraska - Lincoln

DigitalCommons@University of Nebraska - Lincoln

May 1997

\title{
FABRICATION OF MICRON SCALE MAGNETIC NICKEL FEATURES BY SELECTIVE AREA ORGANOMETALLIC CHEMICAL VAPOR DEPOSITION
}

D. Welipitiya

University of Nebraska-Lincoln

C.N. Borca

University of Nebrasksa - Lincoln

Peter A. Dowben

University of Nebraska-Lincoln, pdowben@unl.edu

Follow this and additional works at: https://digitalcommons.unl.edu/physicsdowben

Part of the Physics Commons

Welipitiya, D.; Borca, C.N.; and Dowben, Peter A., "FABRICATION OF MICRON SCALE MAGNETIC NICKEL FEATURES BY SELECTIVE AREA ORGANOMETALLIC CHEMICAL VAPOR DEPOSITION" (1997). Peter Dowben Publications. 161.

https://digitalcommons.unl.edu/physicsdowben/161

This Article is brought to you for free and open access by the Research Papers in Physics and Astronomy at DigitalCommons@University of Nebraska - Lincoln. It has been accepted for inclusion in Peter Dowben Publications by an authorized administrator of DigitalCommons@University of Nebraska - Lincoln. 


\title{
FABRICATION OF MICRON SCALE MAGNETIC NICKEL FEATURES BY
}

\section{SELECTIVE AREA ORGANOMETALLIC CHEMICAL VAPOR DEPOSITION}

\author{
D. Welipitiya, C. N. Borca and P. A. Dowben
}

Department of Physics \& Astronomy and the Center for Materials Research and Analysis, University of Nebraska, Lincoln, Nebraska 68588-0111

I. Gobulukoglu, Hong Jiang and B. W. Robertson

Department of Mechanical Engineering and the Center for Materials Research and Analysis, University of Nebraska, Lincoln, Nebraska 68588-0656

Jiandi Zhang

Solid State Division, Oak Ridge National Laboratory, Oak Ridge, Tennessee 37831

\begin{abstract}
:
We demonstrate that it is possible to deposit a wide range of magnetic features, using photoassisted and electron radiation induced selective area organometallic chemical vapor deposition. Large arrays of identical micron to nano scale $\mathrm{Ni}$ features were deposited by these methods. Their magnetic properties were studied by alternating gradient force magnetometry as well as magnetic force microscopy. Our morphological and magnetic measurements show that the structures are spatially well defined, and the magnetic properties are related to the structural shapes of the features.
\end{abstract}

\section{Introduction}

Conventional magnetic media have large variations of local magnetic properties, making them extremely hard to use in ultra high density recording media. With the development of advanced photo-chemical vapor deposition techniques it is now possible to fabricate arrays of prepatterned single magnetic domain structures located uniformly on a nonmagnetic media. Each magnetic domain will then represent a bit which is spatially well defined at a specified location. This is of advantage in that the magnetic bit writing process can be vastly improved while there is a reduction in bit to bit cross-talk. The decrease in noise and error rate could ultimately result in higher density.

Different methods can be adopted to fabricate ferromagnetic structures ranging from micron to nano scale regime. Organometallic chemical vapor deposition (OMCVD) has several attractive features over the conventional techniques which require multiple step processing. OMCVD is potentially a single step selective deposition process. The study of micron scale magnetic dots made by CVD is among the more unusual and challenging tasks in the area of magnetism, but the magnetic characterization of materials fabricated by this technique is limited [1]. For the deposition of contaminant free metal features, the organometallic compound should satisfy 
several criteria as noted elsewhere [2]. Thus understanding the surface chemistry of the CVD compounds is essential, as has been done [3]

We have been able to fabricate micron scale arrays of geometrically defined ferromagnetic nickel structures by photolysis of nickelocene $\left[\mathrm{Ni}\left(\mathrm{C}_{5} \mathrm{H}_{5}\right)_{2}\right]$.

\section{Experimental}

Selective area chemical vapor deposition was carried out in an ultra high vacuum chamber which was equipped with a quadrupole mass spectrometer (Dycor) for thermal desorption studies, and a single pass CMA and a nitrogen laser, as described elsewhere [4]. The base pressure of this system was maintained at $5 \times 10^{-10}$ torr. Fabrication of nickel containing features by photolysis was carried out on $\mathrm{Si}(111)$ substrates which were mounted on a load lock manipulator system that was capable of introducing multiple samples into the system. During deposition nickelocene vapor pressure was carefully monitored and kept at a pressure of $3 \times 10^{-5}$ torr. Incident radiation for photolysis was supplied by a commercial (Molectron) $\mathrm{N}_{2}$ laser with a wave length of $337 \mathrm{~nm}$ which corresponds to an energy of $3.69 \mathrm{eV}$. A quartz lens was used to focus the beam onto the $\operatorname{Si}(111)$ substrate. A metal grid with a spacing of $20 \mu \mathrm{m} \mathrm{x}$ $20 \mu \mathrm{m}$ was placed to restrict radiation as well to act as a grating. Arrays of $\mathrm{Ni}$ features with different shapes were fabricated by changing the focal position of the quartz lens. During irradiation, mass components were detected by the quadrupole mass spectrometer operated in the pulse counting mode.

Nanoscaled nickel features were drawn by a Vacuum Generators microscope model HB5 scanning transmission electron microscope (STEM) modified to admit sublimed nickelocene, as previously described elsewhere [5]. Deposition was carried out after gradually admitting nickelocene up to pressure ranges of $10^{-7}$ torr. To enhance the adsorption, the substrate was kept at temperatures below $150 \mathrm{~K}$. Decomposition rates were monitored simultaneously with a quadrupole gas analyzer.

\section{Results and Discussion}

Figure 1 shows a magnetic force microscopy (MFM) image of a sample prepared by OMCVD. A commercially available microscope with magnetized tips was utilized (Nanoscope III, Digital Instruments) as described elsewhere [4]. An area of $40 \times 40 \mu \mathrm{m}^{2}$ scan shows parallel bars of nickel features fabricated in a larger array. The MFM images as well as kerr microscopy images clearly shows that the nickel features are ferromagnetic, as expected, and are seen to be spatially well separated. The integrated volume of the particles is in rough agreement with the magnetization measurements [4]. The hysteresis loops shown in figure 2 provide strong evidence that the magnetization is largely in-plane.

Figure 4a shows an in-plane magnetic hysteresis loop from the array of nickel squares (Fig. 3a). The loop was measured by a commercial alternating gradient force magnetometer. The 
saturation field is about $1 \mathrm{kOe}$, and its coercivity is approximately $50 \mathrm{Oe}$. The ratio of the remanence to the saturation magnetization is 0.18 . The hysteresis loops in both the in-plane and perpendicular configurations are nearly identical. This may be because the demagnetization effects of the film are similar in both orientations, since the size of nickel structures is rather small.

To demonstrate the influence of shape on the magnetic properties, we made arrays with differently shaped Ni features. To do this with the same mask, we changed the diffraction condition so that the laser illuminated a different pattern. Figures $3 b$ \& $c$ show the SEM images of an array of nickel features deposited under such conditions. These patterns are very different from the square shaped figures. These films consist of spatially well separated nickel bars within the illuminated area as well as disks. The size of these features were about $3 \mu \mathrm{m} \times 17 \mu \mathrm{m}$ and the diameter of the disks were about $8 \mu \mathrm{m}$.

The hysteresis loops for these features are shown in Fig. $4 \mathrm{~b} \& 4 \mathrm{c}$. Besides the differences in saturation magnetization, determined by the total amount of nickel, the hysteresis loop shape is rather different from that for the array of square-like features (Fig. 4a). The ratio of remanence to saturation is much larger for the features with parallel bars, and the saturation field is slightly lower compared to the square features. The disk features on the other hand possess the lowest coercivity as well as the saturation field. These differences indicate that the hysteresis dynamics are dependent upon the shape of even small volume Ni structures. Systematic studies of different patterns are planned, and will lead to an improved fundamental understanding of magnetic dynamics. Those studies are currently underway. The saturation magnetization of the entire array of nickel dots is consistent with the magnetic properties of nickel, if the integral volume of all the nickel features is considered. It may be that the saturation magnetization is, therefore, not dominated by shape for features of these dimensions, but rather by the composition of the material.

We have proved that fabrication is possible by electron induced radiation. This was achieved by using a scanning transmission electron microscope. Initial deposition studies were undertaken on films of carbon (10 nm thick) or SiO (about $100 \mathrm{~nm}$ thick) supported over the openings in 200 mesh $3 \mu \mathrm{m}$ copper grids. Depositions were performed with an electron energy of $100 \mathrm{keV}$ and with electron beam diameters in the range from under $1 \mathrm{~nm}$ to more than $10 \mathrm{~nm}$. The field emission source and optical system are well suited to stable focusing and scanning of the electron beam under electronic control. Also important, the morphology, structure and other properties of the deposits can be examined in situ with lateral spatial resolution down to about 1 or $2 \mathrm{~nm}$ since the substrates are so thin. Figure 5 shows two lines drawn in this manner.

\section{Summary}

Our results suggest that it may be possible to make features with a sufficiently small volume so as to limit each feature to a single domain. We have deposited micron- and nano scale $\mathrm{Ni}$ structures by using photoassisted and electron radiation induced selective area organometallic chemical vapor deposition. Drastically different Ni features were obtained by manipulating the 
laser diffraction conditions. Their magnetic properties are correlated with the shape of the $\mathrm{Ni}$ features. This deposition method demonstrates a new approach for novel device fabrication.

\section{Acknowledgments}

This work is supported by Department of Energy (No. DE-FG02-95ER 12177.A000), and the

Office of Naval Research through grant no. 96PR06441-00.

\section{References}

[1] L. M. Falicov et. al. J. Mater. Res. 5,1299 (1990)

[2] N. M. Boag, and P. A. Dowben, Designing Organometallics for Vapor Phase Metallization of Plastics, Metallized Plastics 4: Fundamental and Applied Aspects. edited by K. L. Mittal (Plenum, New York. 1996)

[3] D. Welipitiya, C. Waldfried, C. N. Borca. P. A. Dowben, I. Gobulukogulu. Hong Jiang and B. W. Robertson (submitted)

[4] D. Welipitiya. Y, L. He, Jiandi Zhang. P. I. Oden, T. Thundat, R. J. Warmack. I. Gobulukoglu, Z. S. Shan, D. J. Sellmyer, and P. A. Dowben J. Appl. Phys. 80. 1867 (1996)

[5] D. Welipitiya, A. Green. J. P. Woods, and P. A. Dowben J. Appl. Phys. 79. 8730 (1996)
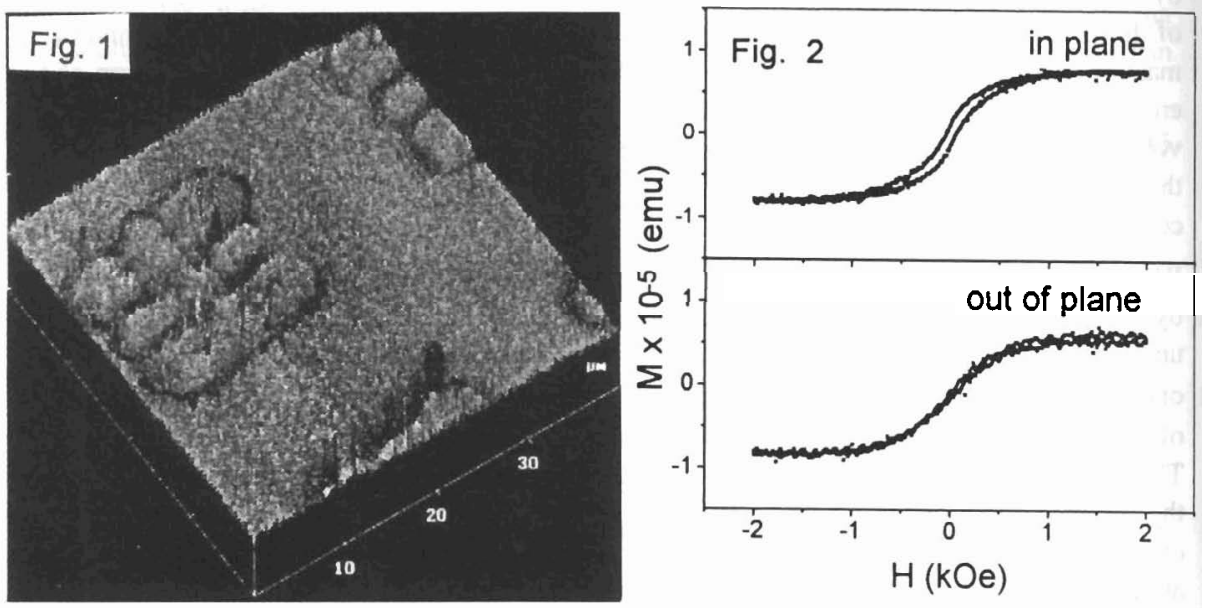

Fig. 1. A $40 \times 40 \mu \mathrm{m}^{2}$ area showing a MFM image. The dimensions are less than $20 \times 20 \mu \mathrm{m}^{2}$ for the arrays of bars with an average height of each $\mathrm{Ni}$ bars of about $300 \mathrm{~nm}$ to $600 \mathrm{~nm}$.

Fig. 2. Out of plane and in-plane hysteresis loops obtained from an alternating gradient magnetometer for the same feature 


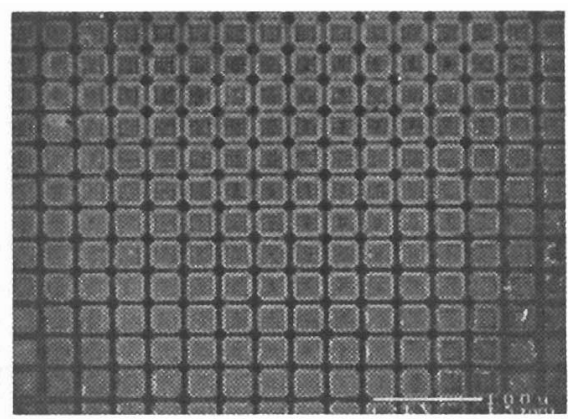

Fig. 3 a

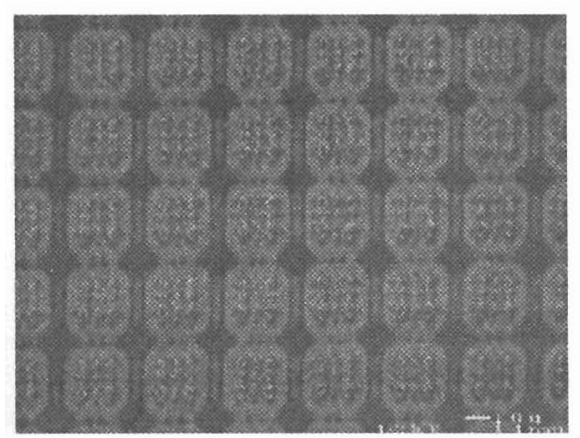

Fig. $3 \mathrm{~b}$
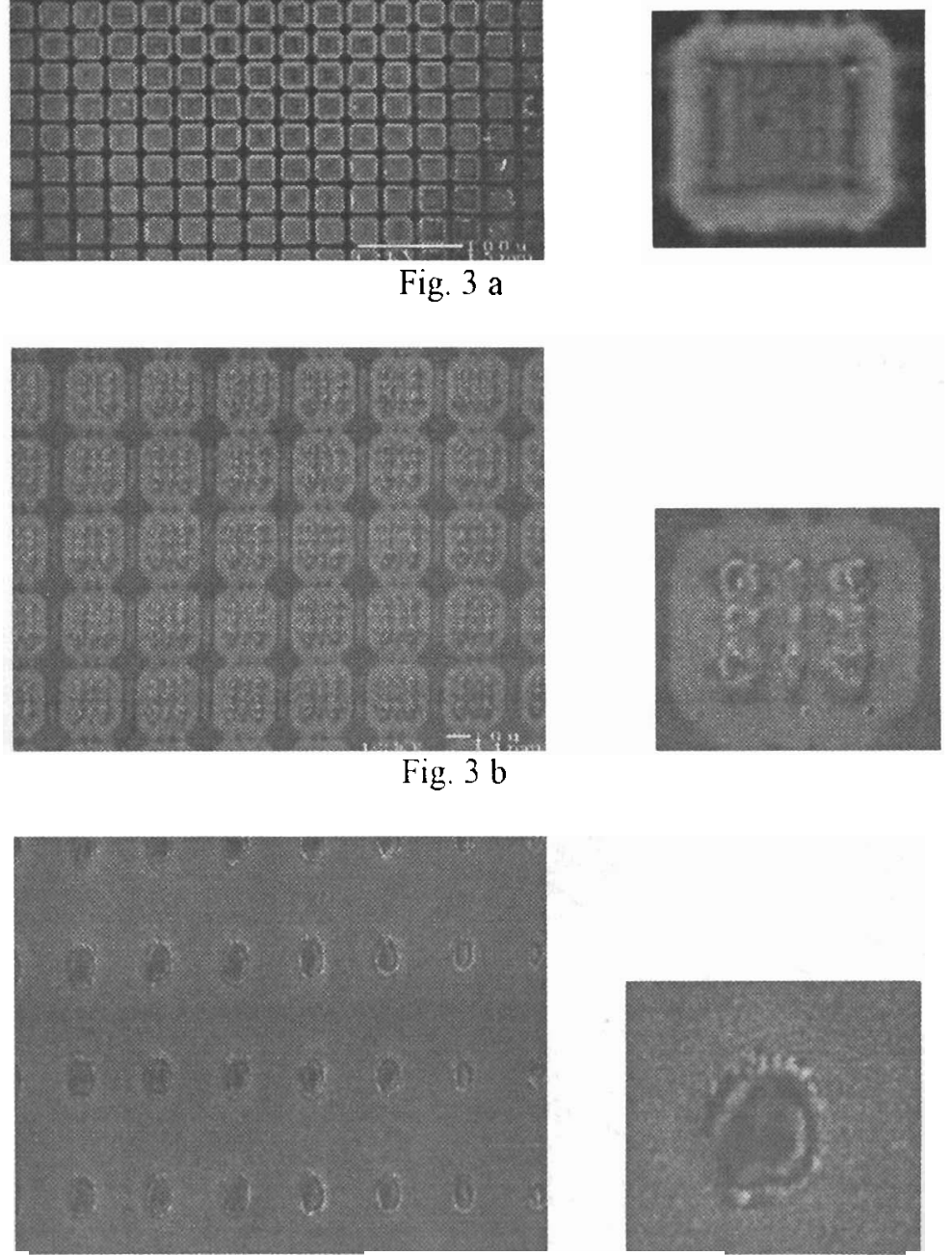

Fig. $3 \mathrm{c}$

Scanning electron microscope images of nickel features that was fabricated by changing the laser diffraction conditions. Fig. 3a is an array of squares of about $18 \mu \mathrm{mx} 18 \mu \mathrm{m}$ in dimension, fig. $3 \mathrm{~b}$ shows a clear diffraction pattern of the nickel features (which are $3 \mu \mathrm{m} \mathrm{x}$ $17 \mu \mathrm{m}$ bars), fig. $3 \mathrm{c}$ is an array of nickel disks with a diameter of about $8 \mu \mathrm{m}$ 


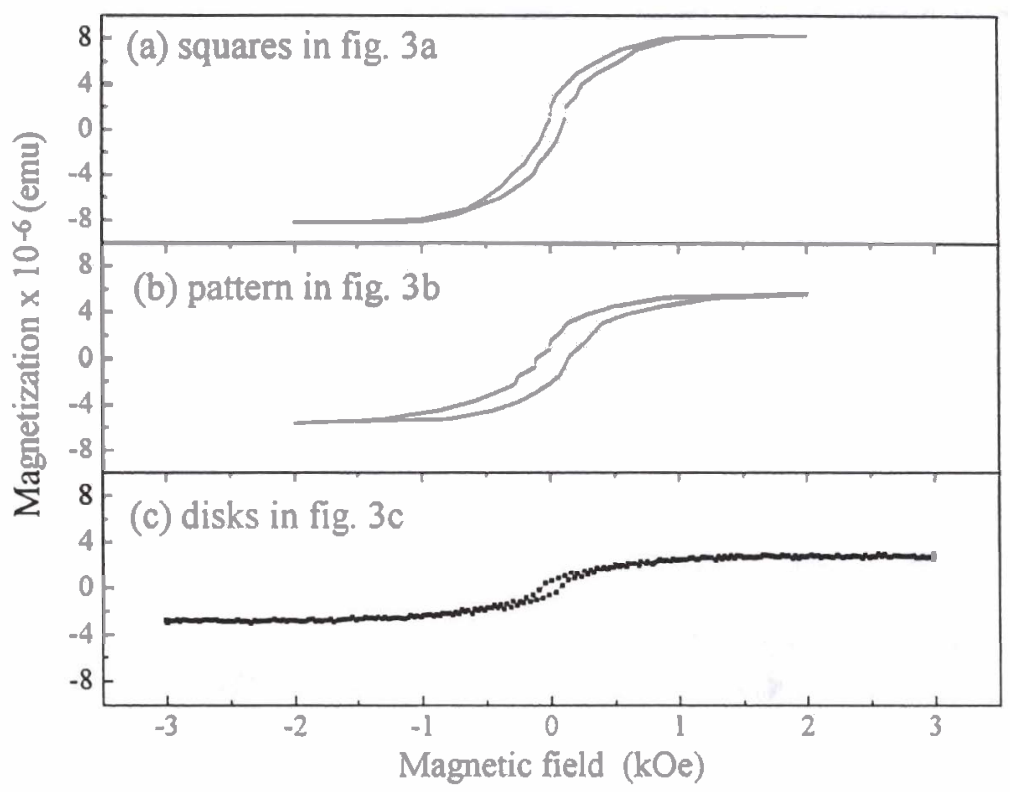

Fig. 4 Hysterisis loops measured by alternating gradient force magnetometer

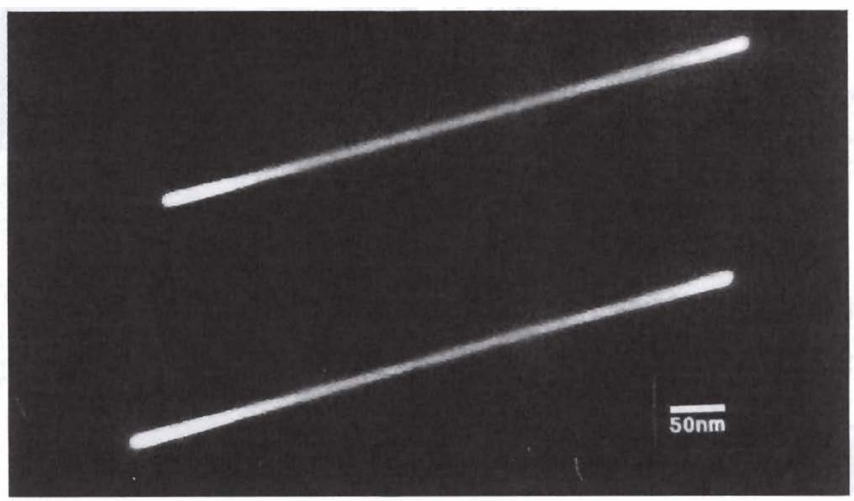

Fig. 5 An annular dark field STEM image of deposits fabricated by electron beam induced OMCVD form nickelocene. Thickness of these lines are in the range of $10-14 \mathrm{~nm}$. 